\title{
Model Fidelity of Assertive Community Treatment for Clients With First-Episode Psychosis: A Target Group-Specific Application
}

\author{
M. J. M. Verhaegh · I. M. B. Bongers • \\ H. Kroon · H. F. L. Garretsen
}

Received: 3 August 2007/Accepted: 25 September 2008/Published online: 16 October 2008

(c) The Author(s) 2008. This article is published with open access at Springerlink.com

\begin{abstract}
Assertive community treatment (ACT) is described as a team treatment model designed to provide assertive, outreaching, comprehensive, community-based, rehabilitation-oriented and supportive psychiatric services for people with severe mental illness as reported by Drake et al. (Psychiatr Serv 52: 179-182, 2001) and Teague et al. (Psychiatr Serv 68: 216-232, 1998). This study explores variations in the way the original components of ACT are implemented for the target group of clients with a firstepisode psychosis, and establishes whether these variations lead the treatment model to a higher, more valuable, outcome level. The study also describes how to achieve this optimally effective application of target group-specific treatment services.
\end{abstract}

Keywords ACT $\cdot$ First-episode psychosis $\cdot$ Model fidelity

\section{Introduction}

Assertive community treatment (ACT) is a well-known evidence-based practice (EBP) that is frequently applied because of its positive impact on, in particular, the target

M. J. M. Verhaegh $(\bowtie)$. I. M. B. Bongers

Institute of Mental Health Care, 909, 5600 Eindhoven,

The Netherlands

e-mail: mjm.verhaegh@ggze.nl

M. J. M. Verhaegh - I. M. B. Bongers - H. F. L. Garretsen Department of Tranzo, University of Tilburg, Tilburg, The Netherlands

H. Kroon

Department of Reintegration and Community Care,

Trimbos Institute Netherlands, Utrecht, The Netherlands group of severely mentally ill persons (Marshall and Lockwood 2003; Drake et al. 2001; Dixon 2000; Teague et al. 1998; Mueser et al. 1998). Nevertheless, some criticize ACT for being too costly or too intensive, and because not all studies show the same effect sizes. The latter can probably be attributed to poor model fidelity in the experimental condition and to the improved quality of the examined 'care as usual' (Billings et al. 2003; Killaspy et al. 2006). Regarding the high costs of ACT, intensive treatment with a caseload of 1:10 applied in times of economic recession has provoked criticism (Fenwick and Byford 2005; Test and Stein 2001; Byford et al. 2000); however, this does not prove that ACT is not cost-effective on the long term. Finally, some argue that resources should not be spent too quickly and to the full extent; a steppedcare approach is suggested by these critics. However, when it becomes obvious that low-intensity care is not (sufficiently) effective, it is justified to implement more intensive alternatives. This way of assigning care avoids taking responsibility away from the client and ensures e.g. hospitalization in the client's own surroundings (Davison 2000).

Why ACT for Clients with a First-episode Psychosis?

First of all ACT is increasingly and successfully applied for clients with a first-episode psychosis (Petersen et al. 2005; Nordentoft et al. 2003). Both from literature and own clinical experience in the last 3 years we know what percentage of the total group of clients will have a relapse but we don't know exactly who in specific will relapse (Wiersma et al. 1998; Vlaminck 2003; Addington et al. 2007). For this reason we chose to apply ACT for the total group of clients. Events in the first 3-5 years after the appearance of the first positive symptoms of psychosis (the critical 
period) determine the future course of the recovery process and functioning of the client (Spencer et al. 2001; McGlashan 1999; Scully et al. 1997).

A positive correlation has been shown between improved outcome of treatment and a shorter duration of untreated psychosis (DUP) (Marshall et al. 2005; McGlashan 2005; McGorry et al. 2005; McGorry and Pelosi 2004; Norman et al. 2005; Perkins et al. 2005). An assertive approach of an ACT-team towards referred clients could be a meaningful feature in shortening the DUP also (Nordentoft et al. 2008). Furthermore research demonstrates the cost-effectiveness of ACT; due to decreasing usage of clinical services the total costs were $20 \%$ lower than 'care as usual' (McGorry et al. 2007; Jeppesen et al. 2005).

\section{Importance of Model Fidelity}

Both the founders and those who adapt ACT emphasize the importance of fidelity in implementing the ACT; a positive outcome is attributed to full implementation of the original model (Burns et al. 2002; Drake et al. 2001; McGrew and Bond 1995a; Priebe et al. 2004; Test and Stein 2001; Weaver et al. 2003). When applying ACT to a new target group it has to be precluded that the outcome (or absence thereof) can be attributed to poor fidelity (Kuipers et al. 2004). A pilot study has shown that ACT in the Netherlands has many shortcomings with regard to model fidelity (van Dijk et al. 2004).

Effect studies have shown the importance of determining model fidelity in both the experimental and the control condition. Studies in the UK noted that care as usual contains many aspects of ACT (Burns et al. 2002). This was partly the explanation for the smaller difference between the effects of the two conditions compared with the results of earlier studies from the USA.

\section{Target Group-Specific Applications}

Mowbray et al. (2003) distinguish between intentional adaptation of EBP and adapting a model unintentionally. Unintentional adaptation often occurs due to poor knowledge of the model one wants to apply, and an insufficient check on actual practice and implementation of the model. In both cases this results in reverting to old habits and losing the EBP.

The consequences and disadvantages of unintentionally applied adaptations are associated with the importance of a high fidelity adaptation of EBP (such as described above). Intentional adaptations enable to justify the choices made, to compare the adapted model to the original, and to establish the level of (increased) effectiveness (Mowbray et al. 2003).
A high fidelity implementation of EBP means a doctrinal operation (Barkham and Mellor-Clark 2003). In practice, however, circumstances may occur that provide reasons to adapt or modify EBP. Adapting the original model purposively is possible and sometimes even necessary, e.g. in case of a new insurance system or divergent geographical circumstances. Another reason for purposively tailoring an EBP is to apply that practice in a totally new or slightly different target group (Bond et al. 2000; Mowbray et al. 2003; Henskens et al. 2005; McGrew et al. 1995b).

Variation is also possible on the condition that it happens judiciously and to a limited extent. EBP's have several critical components that determine the essence of the model. Changing these components implies loss of fidelity and consequently decreased effectiveness. Making changes to the non-critical components has been shown to improve the effectiveness of the model (Bond et al. 2001).

The following features of ACT are considered to be critical (Table 1): a multidisciplinary team, integrated care, a team approach, low caseload, within the community, psychopharmacologic treatment, care is aimed to everyday needs, quick crisis intervention, assertive attitude, individual approach, and the offer is preferably not timelimited (Bond et al. 2001).

The present study explores the possibility of achieving a better treatment outcome by intentionally applying a 'full implemented' ACT-model to the demands of a new group of clients with first-episode psychosis. Hereby we followed the above mentioned insights in intentionally changing EBP's and describe how it is achieved.

Table 1 Critical and non-critical components of ACT (Bond et al. 2001)

\begin{tabular}{ll}
\hline Critical components & Non-critical components \\
\hline Multidisciplinary team & Intake rate \\
Integrated care & Staff continuity \\
Team approach & Practicing leader \\
Low caseload & Program meeting \\
Act in community & Discharge planning \\
& responsibility \\
Psychopharmacologic treatment & No dropout \\
Care is aimed to everyday needs & Work with support system \\
Quick crisis intervention & Group substance abuse \\
& treatment \\
Assertive attitude & Dual disorder model \\
Individual & Hospital admission \\
& responsibility \\
The service is aimed & Team complement \\
not-time-limited & Explicit admission criteria \\
& Staff capacity \\
\hline
\end{tabular}


Three research items are addressed: (1) the fidelity rate of ACT in this research to mark the starting point; (2) the degree to which the present services are demand oriented; and (3) the effects of implementing the suggested improvements whilst preserving the critical components.

\section{Methods}

In July 2004 a mental healthcare organization in the southern part of the Netherlands (Mental Healthcare Eindhoven) started to treat a group of clients according to the principles of ACT. The target group consists of all customers with a first episode psychosis (excluding substance-induced psychotic disorders), generally in the age group 18-35 years. The catchment area comprises 450,000 inhabitants of whom 210,000 live in a city.

The fidelity of ACT was measured three times; in September 2004, in November 2005 and again in March 2007, using the Dartmouth Assertive Community Treatment Scale (DACTS) (Teague et al. 1998). DACTS measurements were carried out by an independent researcher and the first author; data were collected jointly and later scored independently. This resulted in a high interrater reliability; of the 28 items only 2 items showed a difference of maximally 1 point on a 5 -point scale.

The DACTS consists of 28 items, each rated on a 5point behaviourally-anchored scale with a score of 4.2 or more indicating 'full implementation', 3.0-4.2 indicating 'moderate implementation', and 1.0-3.0 indicating a 'low degree of implementation' (Salyers et al. 2003).

After 1 year the ACT team received practice-based feedback concerning the degree to which, according to the customers and caregivers, the received services correspond to their needs/demands (Barkham and Mellor-Clark 2003). All clients $(N=70)$ received a questionnaire consisting of two open questions: What do you like about ACT? and Which of the offered services do you not like? A covering letter requested the caregiver to answer the questions together with the client. In case the client was unable to answer the questions, the caregivers were asked to complete the questionnaire instead.

A team member and a program leader analyzed the qualitative data and, compiled an overview of the positive/ negative responses, and highlighted the four topics that appeared to need improvement. These topics/points of interest were presented to four key figures (well-informed colleagues who were not a team member) who recognized the impact of these topics during the last year and judged them to be essential.

The modified data were presented and discussed at a meeting with clients and their caregivers $(N=75)$ and staff members $(N=10)$. The participants were divided into eight subgroups, with equal numbers of men/women and clients/caregivers. The subgroup discussions were supervised by independent chairpersons who were well informed about ACT; none was a team member. Uniformity of the discussions was promoted by the use of standard protocols. The subgroups held discussions for $1.5 \mathrm{~h}$ concerning the points of interest.

In November 2005 the above-described method was repeated. Clients and caregivers were again asked for their feedback on the services received. The data were again discussed, as previously, during a (family) group meeting.

- All authors that contributed to this study state that there are no conflicts of interest and declare to be responsible for all content in this article.

- The authors published on this topic in the Dutch journal: Verhaegh M., Bongers, I., Kroon, H., \& Garretsen, H. (2007). Assertive Community Treatment bij cliënten met een eerste psychose. Modelgetrouwheid en doelgroepspecifieke aanpassingen. Tijdschrift voor Psychiatrie. 49 (11). p. 789-798.

\section{Results}

The first measurement (September 2004) of model fidelity produced an average DACTS implementation score of 3.5 (Table 2).

The strikingly low score on the Subscale services (2.7) was caused by the fast inclusion of clients at the start of the project, the low frequency of contact per client, and the absence of a double-diagnosis expert and of a peer group worker. The score on the subscale Team structure was negatively affected when a staff member left at the start of the project, and a substance abuse expert was lacking. The subscale Organization was negatively influenced by a high inclusion rate and poor collaboration with the acute care ward in the first months. The second measurement (November 2005) produced a total score of 4.3 indicating 'complete implementation'. The improved score is a result

Table 2 DACTS scores ${ }^{\mathrm{a}}$ of fidelity assessment in 2004, 2005 and 2007

\begin{tabular}{llll}
\hline & September 2004 & November 2005 & March 2007 \\
\hline Team structure & 4.2 & 4.6 & 4.4 \\
Organization & 3.6 & 4.8 & 4.4 \\
Services & 2.7 & 3.5 & 3.7 \\
Total score $^{\mathrm{b}}$ & 3.5 & 4.3 & 4.2 \\
\hline
\end{tabular}

${ }^{\text {a }}$ DACTS score range is from 1 to 5 ; a higher score indicates a higher fidelity

b The total score is the mean of 3 sub scores (team structure, organization and services) 
of successfully dealing with the points of interest mentioned above, and completing the team with the missing experts.

The third DACTS-score in March 2007 showed a stable fidelity level (total score was 4.2), which indicates that after the target group-specific applications the ACT-model is still 'full implemented'.

Of the 70 questionnaires distributed, 54 were returned (response $77 \%$ ). In $20 \%$ of the cases the client filled in the questionnaire alone mainly because of the lack of (or a poor) social network. The majority of the questionnaires $(60 \%)$ were filled in by the clients together with the caregiver(s). The caregiver(s) answered alone in $20 \%$ of the cases, mostly because their client was in a crisis or was not motivated to respond.

In their answers, 36 respondents $(66.7 \%)$ mentioned only positive characteristics of the services, 16 (29.6\%) reported both positive and negative aspects, and 2 respondents $(3.7 \%)$ gave only negative feedback (Tables 3,4$)$.

Table 3 Experienced positive features of service model mentioned by respondents $(N=54)$

\begin{tabular}{lcc}
\hline & $\%$ & $N$ \\
\hline Demand oriented, good care & 63 & 34 \\
Easy to contact because of team approach & 50 & 27 \\
Support to parents & 37 & 20 \\
The intensity of the services & 33 & 18 \\
Care in community & 9 & 6 \\
Offered psycho-education & 6 & 4 \\
Vocational and school support & 6 & 4 \\
Capable and enthusiastic team & 6 & 4 \\
Peer group support & 6 & 4 \\
Well-informed team & 6 & 4 \\
\hline
\end{tabular}

Table 4 Experienced negative features of service model mentioned by respondents $(N=54)$

\begin{tabular}{lrr}
\hline & $\%$ & $N$ \\
\hline Contactability after office hours & 24 & 13 \\
Communication should be better & 13 & 7 \\
Insufficient contact with issuing authority & 13 & 7 \\
Services are not assertive enough & 13 & 7 \\
Insufficient vocational support & 6 & 4 \\
Too little support on financial issues & 6 & 4 \\
Not enough peer group contacts & 6 & 4 \\
Search for accommodation takes too long & 6 & 4 \\
Not enough contact with parents/caregivers & 6 & 4 \\
Concerns about new crises & 6 & 4 \\
Insufficient services & 6 & 4 \\
Appointment system not satisfactory & 6 & 4 \\
\hline
\end{tabular}

The positive responses were generally in agreement with the critical components of ACT. The respondents mentioned the multidisciplinary team approach, tailored care, integrated care, the low caseload, community in care, and well-organized crisis intervention. The assertive attitude was considered positive, but some criticisms were also reported (Table 4). Not specifically mentioned by the respondents were: pharmacological therapy, care aimed not to be time-limited, and focusing on everyday needs.

Four points of interest emerged from the family group meeting:

(1) Communication between the ACT team and the parties involved (including clients/caregivers); a need for the following improvements were indicated:

- Clients and caregivers emphasized the need for cooperation with support systems (DACTS item 24). They requested better information about ACT (e.g. a folder, internet site or newsletter), the use of e-mail communication, and more attention paid to inform primary healthcare. The team must be more explicit about their expectations concerning the role of parents in the treatment process. The respondents stress the importance of family psychological training. This point also concerns closer interpretation of DACTS item 12, i.e. clear criteria of inclusion. Caregivers complain, mostly afterwards, about the long delay before referral to ACT.

- Caregivers ask team members to act more assertively towards primary healthcare professionals and other partners in the network such as housing companies, financial institutions, or payment agencies. Agencies wait too long before they indicate that something is threatening to go wrong.

- A good level of communication is associated with the small-scale of ACT (DACTS item 22, intensity of services). The small scale of operation should be maintained to guarantee optimal communication.

(2) Service accessibility and availability of the team. The clients report shortages regarding contact, especially (telephonic availability) after office hours. This applies to both regular contacts with a team member and crisis intervention (DACTS item 15, responsibility for crisis services). Respondents indicate that ACT services during office hours with an additional crisis intervention ward are often inadequate.

(3) Match between care demand and services offered. There is a need for more variations in therapy, e.g. peer group meetings and family/caregiver groups. 
Caregivers indicate that they also need psychological training. Caregivers also want more knowledge and support concerning legislation, financial and vocational matters. There is also a need for occupational activities and leisure support. More attention should be paid to pharmacotherapy; especially the side effects of medication (problems with concentration, extra pyramidal symptoms, fatigue, impotence). The results are related to DACTS items 24 (cooperation with support system), 7 and 8 (specific attention and expertise of nurses/psychiatrists) and 10 (the capacity of vocational trainers).

(4) Attitude of the professionals. This was judged to be too non-committal. Caregivers should have a more assertive attitude, as described in the original model. Professionals must act more directly and more proactively.

After 1 year 88 questionnaires were distributed; after one reminder 67 were returned (response 76\%). This time, in $27 \%$ of the cases the client filled in the questionnaire independently; in $22 \%$ of the cases the questionnaires were filled in by the clients and caregiver(s) together, and in $51 \%$ the caregiver(s) answered the questionnaires alone.

In their answers, 27 respondents (40\%) mentioned only positive characteristics of the services, $39(58 \%)$ reported both positive and negative features, and 1 respondent gave only negative feedback.

The evening meeting was attended by about 100 persons; 80 were clients/caregivers and 20 were professionals. The positive responses were similar to those reported in the first year. The level of availability in the weekends and evenings had been extended and is now considered a positive point. The professionals showed a more assertive attitude, and the increased attention to clients' finances has also become a positive point.

New critical points emerging are: availability during the daytime, the busy agenda of professionals when an appointment is needed on the short term, and appointments are changed too often.

\section{Discussion}

This study investigated whether target group-specific applications on bases of a 'full implemented' ACT-model improve the outcome, and described how this can best be achieved. We examined whether the original ACT model in this study was fully implemented. Subsequently, data were collected that indicated specific applications to be made on the original model when applied to clients with a first-episode psychosis. Then, positive and negative items were discussed against the background of the (non-) critical components of the model, and suggestions for improvements were made.

After 1 year of ACT the model has been fully implemented and clients/caregivers indicate that the provided services adequately meet the critical components of the original ACT model and answer the care demands of both clients and caregivers. Whether quantitative data will produce the same positive outcome is not yet established; our research data are still being analysed.

Based on the results of the questionnaires and the family group meetings, the model has been applied according to the demands of the target group and caregivers on a number of points.

Regarding communication: the target group now makes more use of latest media such as SMS and e-mail, as do the professionals. The team will inform regional parties and colleagues more effectively about the ACT.

Regarding accessibility and availability: accessibility has been successfully extended to (parts of) the evening and the weekends; the extra hours have been synchronised with school and working hours. There does not seem to be a need for a separate crisis intervention service because clients have more frequent contact with caregivers. The emergency telephone can also be used for less urgent matters. All these applications are positively appreciated.

Clients and caregivers would like better harmonisation between services and care demands; i.e. they ask for services to focus more specifically on the target group and caregivers, and give more attention to support with regard to financial problems, vocational and pharmacological issues. The attention paid to financial matters has improved according to both clients and caregivers.

Finally, caregivers and clients asked for a more assertive attitude of professionals when clients do not comply with the treatment plan. This is a characteristic of ACT, but had not been strongly implemented. It seems, however, that the present target group needs less assertiveness than the group with severe mental illness. For example, most of our young people seemed to comply easily and there was almost no dropout. Nevertheless, the team did act more assertively and pro-actively, especially in situations that threaten to go wrong. It became clear that especially the caregivers appreciate this positively.

The new points of attention (accessibility, availability and planning of appointments) have resulted in increased capacity in the secretarial office.

Neither clients nor caregivers mentioned the characteristic 'not-time-limited care'; this is because the team had not yet formulated a discharge policy. Later on, because of the large number of admissions and limited treatment capacity, the team placed the item 'not-time-limited' on the agenda. The team decided to transfer care to a case manager 3 years after the appearance of the first symptoms of 
psychosis. However, the results of the OPUS study (Bertelsen et al. 2008). have shown that when ACT stops after 2 years, after an additional 3 -year period the client reverts to the same level of functioning as clients who received care as usual only, i.e. the health advantages achieved with ACT disappeared completely. This seems to show that during the critical period ACT is indicated for 5 years rather than 3 years.

The results presented here relate to the target group of clients with a first-episode psychosis. Based on the incidence rates it has been calculated that eight of the ten persons with a first-episode psychosis belong to the target group of the ACT team treatment. In the present study, $77 \%$ of this group have been represented and we have no reason to assume that this proportion is not representative for the total population. These results, however, may be influenced by the local circumstances, i.e. the service model has been applied for only 2 years, and the team members are ambitious and enthusiastic about this novel treatment.

\section{Conclusions and Recommendations}

According to the moderate scores on the DACTS, implementation of the current Dutch mental healthcare ACT services shows a poor level of fidelity (van Dijk et al. 2004). It seems that implementations of the model occur coincidentally rather than intentionally. Local and practical circumstances tend to determine the content and structure of the model.

This article describes an intentional target group-specific application of an EBP based on feedback from the clients and caregivers. The goal was to achieve a treatment-model that responds to the specific care demands of the present target group and afterwards to examine whether it still meets the (critical) characteristics/components of ACT. The suggested points of interest of clients and caregivers match the characteristics of the original ACT model. The service can be improved by better compliance with the original features or a more demand driven variant of the existing characteristics. None of the suggestions made by the clients and caregivers were incompatible with or missing from the DACTS items. Therefore, our results indicate that all (critical) components of ACT are suitable for this target group. One year after the target group specific applications were realized, the model is still 'full implemented' according to the DACTS-score.

For our target group of clients the desired applications were: communication with target group members and network partners, and more emphasis on aspects of daily living (e.g. accommodation, finances, work, schooling) and the consequences of choices to be made (taking into account schooling, working hours and (side) effects of medication. Involving caregivers in the healthcare process (e.g. family groups, psycho-education) was of great importance for the clients and caregivers and is considered a possible critical feature for this target group. Another critical item was related to greater availability of vocational rehabilitation expertise. A final new feature of future ACT-teams could be an assertive approach towards referral parties. In our region the DUP is less than a month likely due to the presence of this feature.

In this study a systematically evaluation of both the (fidelity of an) EBP and to what extent it meets the needs of families and clients has proven to be successful and, more in general, seems to be crucial to achieve an optimal application of EBP's for new target groups. An annual email questionnaire in combination with a meeting of clients and caregivers appears to be an effective feedback method to improve the services and to evaluate their effectiveness.

Open Access This article is distributed under the terms of the Creative Commons Attribution Noncommercial License which permits any noncommercial use, distribution, and reproduction in any medium, provided the original author(s) and source are credited.

\section{References}

Addington, D., Addington, J., \& Patten, S. (2007). Relapse rates in an early psychosis treatment service. Acta Psychiatrica Scandinavica, 115, 126-131.

Barkham, M., \& Mellor-Clark, J. (2003). Bridging evidence-based practice and practice-based evidence: Developing a rigorous and relevant knowledge for the psychological therapies. Clinical Psychology \& Psychotherapy, 10(6), 319-327.

Bertelsen, M., Jeppesen, P., Petersen, L., Thorup, A., Øhlenschlæger, J., le Quach, P., et al. (2008). Five-year follow-up of a randomized multicenter trial of intensive early intervention vs standard treatment for patients with a first episode of psychotic illness: The OPUS trial. Archives of General Psychiatry, 65(7), $762-771$.

Billings, J., Johnson, S., Bebbington, P., Greaves, A., Priebe, S., Muijen, M., et al. (2003). Assertive outreach teams in London: Staff experiences and perceptions: Pan-London assertive outreach study, Part 2. British Journal of Psychiatry, 183, 139-147.

Bond, G., Drake, R., Mueser, K., \& Latimer, E. (2001). Assertive community treatment for people with severe mental illness. Critical ingredients and impact on patients. Disease Management \& Health Outcomes, 9(3), 142-157.

Bond, G., Evans, L., Salyers, M., Williams, J., \& Kim, H. (2000). Measurement of fidelity in psychiatric rehabilitation. Mental Health Services Research, 2(2), 75-87.

Burns, T., White, I., Byford, S., Fiander, M., Creed, F., \& Fahy, T. (2002). Exposure to case management: Relationships to patient characteristics and outcome: Report from the UK700 trial. British Journal of Psychiatry, 181, 236-241.

Byford, S., Fiander, M., Torgerson, D., Barber, J., Thompson, G., Burns, T., et al. (2000). Cost-effectiveness of intensive v. standard case management for severe psychotic illness: UK700 case management trial. British Journal of Psychiatry, 176, 537543. 
Davison, G. (2000). Stepped care: Doing more with less? Journal of Consulting and Clinical Psychology, 68(4), 580-585.

Dixon, L. (2000). Assertive Community Treatment: Twenty-five years of gold. Psychiatric Services, 51, 759-765.

Drake, R., Goldman, H., Leff, H., Lehman, A., Dixon, L., Mueser, K., et al. (2001). Implementing evidence-based practices in routine mental health service settings. Psychiatric Services, 52, 179182.

Fenwick, E. P., \& Byford, S. M. (2005). A guide to cost-effectiveness acceptability curves. British Journal of Psychiatry, 187, 106108.

Henskens, R., Garretsen, H., Mulder, C. L., Bongers, I., \& Kroon, H. (2005). Fidelity of an outreach treatment program for chronic crack abusers in the Netherlands to the ACT model. Psychiatric Services, 56, 1451-1454.

Jeppesen, P., Petersen, L., Thorup, A., Abel, M. B., Øhlenschlæger, J., Christensen, T., et al. (2005). Integrated treatment of firstepisode psychosis: Effect of treatment on family burden: OPUS trial. British Journal of Psychiatry Supplement, 48, s85-s90.

Killaspy, H., Bebbington, P., Blizard, R., Johnson, S., Nolan, F., Pilling, S., et al. (2006). The REACT study: Randomised evaluation of assertive community treatment in north London. $B M J, 332,815-820$.

Kuipers, E., Holloway, F., Rabe-Hesketh, S., \& Tennakoon, L. (2004). An RCT of early intervention in psychosis: Croydon outreach and assertive support team (COAST). Social Psychiatry and Psychiatric Epidemiology, 39(5), 358-363.

Marshall, M., Lewis, S., Lockwood, A., Drake, R., Jones, P., \& Croudace, T. (2005). Association between duration of untreated psychosis and outcome in cohorts of first-episode patients: A systematic review. Archive of General Psychiatry, 62(9), 975983.

Marshall, M., \& Lockwood, A. (2003). Assertive Community Treatment for those with severe mental disorders, Cochrane Library, Vol. 5, No. 2.

McGlashan, T. (1999). Duration of untreated psychosis in firstepisode schizophrenia: Marker or determinant of course? Biological Psychiatry, 46, 899-907.

McGlashan, T. (2005). Early detection and intervention in psychosis: An ethical paradigm shift. British Journal of Psychiatry, 187, $113-115$.

McGorry, P., Killackey, E., \& Yung, A. (2007). Early intervention in psychotic disorders: Detection and treatment of the first episode and the critical early stages. Medical Journal of Australia, 187(7 Suppl), S8-S10.

McGorry, P., Nordentoft, M., \& Simonsen, E. (2005). Introduction to 'Early psychosis: A bridge to the future'. British Journal of Psychiatry, 187, 1-3.

McGorry, P. D., \& Pelosi, A. J. (2004). Value of early intervention in psychosis. British Journal of Psychiatry, 185, 172.

McGrew, J., \& Bond, G. (1995). Critical ingredients of assertive community treatment: Judgments of the experts. Journal of Mental Health Administration, 23, 113-125.

McGrew, J., Bond, G., Dietzen, L., McKasson, M., \& Miller, L. (1995). A multisite study of client outcomes in assertive community treatment. Psychiatric Services, 46, 696-701.

Mowbray, C., Holter, M., Teague, G., \& Bybee, D. (2003). Fidelity criteria: Development, measurement, and validation. American Journal of Evaluation, 24, 315-340.
Mueser, K., Bond, G., Drake, R., \& Resnick, S. (1998). Models of community care for severe mental illness: A review of research on case management. Schizophrenia Bulletin, 24(1), 37-74.

Nordentoft, M., Jeppesen, P., \& Petersen, L. (2003). OPUS project: A randomised controlled trial of integrated psychiatric treatment in first-episode psychosis. Schizophrenia Research, 60, 297.

Nordentoft, M., Thorup, A., Petersen, L., Øhlenschlæger, J., Christensen, T., Krarup, G., et al. (2008). Does a detection team shorten duration of untreated psychosis? Early Intervention in Psychiatry, 2, 22-26.

Norman, R., Lewis, S., \& Marshall, M. (2005). Duration of untreated psychosis and its relationship to clinical outcome. British Journal of Psychiatry, 187, s19-s23.

Perkins, D., Gu, H., Boteva, K., \& Lieberman, J. (2005). Relationship between duration of untreated psychosis and outcome in firstepisode schizophrenia: A critical review and meta-analysis [Miscellaneous article]. American Journal of Psychiatry, 162, $1785-1804$.

Petersen, L., Jeppesen, P., Thorup, A., Abel, M., Øhlenschlæger, J., Christensen, T., et al. (2005). A randomised multicentre trial of integrated versus standard treatment for patients with a first episode of psychotic illness. British Medical Journal, 331, 602605.

Priebe, S., Fakhoury, W., White, I., Watts, J., Bebbington, P., Billings, J., et al. (2004). Characteristics of teams, staff and patients: Associations with outcomes of patients in assertive outreach. British Journal of Psychiatry, 185, 306-311.

Salyers, M., Bond, G., Teague, G., Cox, J., Smith, M., Hicks, M., et al. (2003). Is it ACT yet? Real-world examples of evaluating the degree of implementation for assertive community treatment. Journal of Behavioral Health Services \& Research, 30, 304-320.

Scully, P., Coakley, G., Kinsella, A., \& Waddington, J. (1997). Executive (frontal) dysfunction and negative symptoms in schizophrenia: Apparent gender differences in 'static' v. 'progressive' profiles. British Journal of Psychiatry, 171, 154-158.

Spencer, E., Birchwood, M., \& McGovern, D. (2001). Management of first-episode psychosis. Advances in Psychiatric Treatment, 7, 133-140.

Teague, G., Bond, G., \& Drake, R. (1998). Program fidelity in assertive community treatment: Development and use of a measure. American Journal of Orthopsychiatry, 68, 216-232.

Test, M., \& Stein, L. (2001). A critique of the effectiveness of assertive community treatment. Psychiatric Services, 52, 13961397.

Van Dijk, B., Roosenschoon, B., Kroon, H., \& Mulder, C. (2004). Modelgetrouwheid van assertive community treatment in Nederland [Model fidelity of assertive community treatment in Holland]. Maandblad Geestelijke volksgezondheid, 59, 931-943.

Vlaminck, P. (2003). De moderne aanpak van psychose [Modern treatment of psychosis]. Uitgeverij Eburon.

Weaver, T., Tyrer, P., Ritchie, J., \& Renton, A. (2003). Assessing the value of assertive outreach: Qualitative study of process and outcome generation in the UK700 trial. British Journal of Psychiatry, 183, 437-445.

Wiersma, D., Nienhuis, F. J., Slooff, C. J., \& Giel, R. (1998). Natural course of schizophrenic disorders: A 15-year follow-up of a Dutch incidence cohort. Schizophrenia Bulletin, 24(1), 75-85. 